\title{
Hemodynamic changes in regular antipsychotic users after adrenaline-containing lidocaine injection under general anesthesia: a prospective study
}

Yoshiki Shionoya ( $\nabla$ yoshiki@tky.ndu.ac.jp )

Nihon Shika Daigaku Fuzoku Byoin https://orcid.org/0000-0001-5012-4907

Eishi Nakamura

Nihon Shika Daigaku Fuzoku Byoin

Gentaro Tsujimoto

Nihon Shika Daigaku Fuzoku Byoin

Takayuki Koyata

Nihon Shika Daigaku Fuzoku Byoin

Asako Yasuda

Nihon Shika Daigaku Fuzoku Byoin

Kiminari Nakamura

Nihon Shika Daigaku Fuzoku Byoin

Katsuhisa Sunada

Nihon Shika Daigaku Fuzoku Byoin

Research article

Keywords: Adrenaline, Antipsychotics, General anesthesia, Interaction, Local anesthesia

Posted Date: March 16th, 2020

DOI: https://doi.org/10.21203/rs.3.rs-17266/v1

License: (a) (1) This work is licensed under a Creative Commons Attribution 4.0 International License. Read Full License 


\section{Abstract}

Background: Local anesthetic containing adrenaline is commonly used in many operations to maintain hemostasis and prolong the duration of anesthesia. Antipsychotic drugs have an a-adrenergic receptor blocking action, and it is thought that $\beta$-adrenergic receptors predominate when adrenaline is administered in combination, thus inducing hypotension. Many general anesthetics have vasodilatory effects, and it is possible that blood pressure may decrease further if adrenaline-containing lidocaine is administered to antipsychotic users during anesthesia. This study aimed to assess the circulation dynamics in regular antipsychotics users administered adrenaline-containing lidocaine under general anesthesia in a dental procedure.

Methods: Participants included 30 patients regularly using antipsychotics (butyrophenone, phenothiazine, and/or atypical antipsychotics) who were scheduled for dental treatment to be performed under general anesthesia. At five minutes after tracheal intubation, the systolic blood pressure (SBP), diastolic blood pressure (DBP), heart rate (HR), and percutaneous oxygen saturation ( $\mathrm{SpO} 2)$ were measured as a baseline. SBP, DBP, HR, and SpO2 were measured 2, 4, 6, 8, and 10 minutes after the injection of $1.8 \mathrm{~mL}$ of $2 \%$ lidocaine $(32 \mathrm{mg})$ with $1: 80,000$ adrenaline $(22.5 \mu \mathrm{g})$ into the oral cavity. Differences in the SBP, DBP, $\mathrm{HR}$, and SpO2 between baseline and at each time point were analyzed using Dunnett's test.

Results: No significant changes were observed in the SBP, DBP, HR, and SpO2 compared to baseline until ten minutes after the administration of adrenaline-containing lidocaine. No adverse events were observed up to one hour after the administration of adrenaline-containing lidocaine.

Conclusions: This study demonstrated that adrenaline used at the usual dose for dental treatment under general anesthesia is unlikely to affect the circulation dynamics of regular antipsychotic users.

\section{Background}

Local anesthetic containing epinephrine provides several advantages; increasing the duration of anesthetic effect, decreasing the systemic toxicity of local anesthetics, providing hemostasis at the surgical site, and enhancing the quality of the neural blockade [1-4]. Since antipsychotic drugs have an $\alpha$-adrenergic receptor blocking action [5], it is thought that when adrenaline is used in combination, $\beta$ adrenergic receptors predominate and peripheral blood vessels are dilated, inducing hypotension. Therefore, lidocaine containing adrenaline should be carefully administered in patients who are being treated with antipsychotics, such as patients with schizophrenia, autism, intellectual disability, and dementia. Okada et al. [6] reported a schizophrenic patient with risperidone overdose who experienced unexpected hypotension in response to noradrenaline infusion. They believe that this unexpected hypotension in response to catecholamine infusion was caused by the a-adrenergic blockade effect of risperidone. However, no prospective study has assessed the effects of the interaction between dental adrenaline-containing lidocaine and antipsychotics on circulatory dynamics. 
Because of uncooperative nature/poor compliance, general anesthesia is often necessary for the dental treatment of regular antipsychotics users. Since many general anesthetics have vasodilatory effects, it is possible that blood pressure may further decrease if adrenaline-containing lidocaine is administered to antipsychotic users during anesthesia. The purpose of the present study was to clarify the circulation dynamics in regular antipsychotics users administered adrenaline-containing lidocaine under general anesthesia in a dental procedure.

\section{Materials And Methods}

This study was approved by the Ethics Committee of The Nippon Dental University School of Life Dentistry Tokyo, Japan (approval number NDU-T-2015-14) and was performed in accordance with their guidelines and the guidelines of the Declaration of Helsinki. It was conducted after clinical trial registration as certified by the International Committee of Medical Journal Editors (trial identification number UMIN000016644). Informed consent was obtained from all individual participants or legal guardians included in the study.

This was a prospective study performed at Nippon Dental University Hospital Tokyo, Japan. Participants included 30 patients regularly using butyrophenone, phenothiazine, and/or atypical antipsychotics for more than three months who were scheduled for dental treatment to be performed under general anesthesia. Patients were excluded from the study if any of the following criteria were met: age $<18$

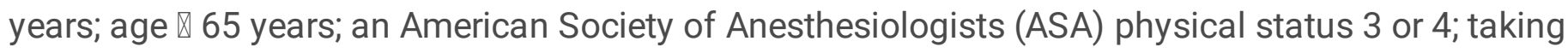
circulatory drugs and/or antidepressants drugs; a history of allergy to lidocaine or any of the other ingredients used in the study; and patients with hypertension, heart failure, diabetes, and hyperthyroidism.

No premedication was administered in any patient. Routine anesthesia monitoring consisted of electrocardiography, pulse oximetry, non-invasive blood pressure, capnography, and Bispectral Index (BIS) monitors. With $100 \%$ oxygen administered from a face mask, general anesthesia was induced with propofol and remifentanil using a syringe pump (TE-332S, Terumo, Tokyo, Japan) after the intravenous line was secured. If or when venous access was difficult to establish, slow induction using sevoflurane was selected and shifted to anesthesia with propofol and remifentanil after losing consciousness. The administration of remifentanil was terminated immediately after nasotracheal intubation using rocuronium bromide $(0.6 \mathrm{mg} / \mathrm{kg})$, and anesthesia was maintained using propofol so as to BIS values between 40 and 60 .

At the point of five minutes after discontinuation of remifentanil, blood pressure, heart rate, and oxygen saturation were measured as a baseline. Immediately after measuring the baseline, $1.8 \mathrm{~mL}$ of $2 \%$ lidocaine $(32 \mathrm{mg})$ with 1:80,000 adrenaline $(22.5 \mu \mathrm{g})$ was administered to the oral cavity via buccal mucosa slowly over 30 seconds with a 30-gauge needle. The systolic blood pressure (SBP), diastolic blood pressure (DBP), heart rate (HR), and percutaneous oxygen saturation (SpO2) were measured 2, 4, 6, 8 , and 10 minutes after completing the administration of adrenaline-containing lidocaine. When the SBP fell below $70 \mathrm{mmHg}$, the cardiovascular agent was administered, and the administration time, drug name, 
and dosage were recorded. From that point, 10 minutes after completing the administration of adrenalinecontaining lidocaine, dental treatment was started, remifentanil administration was resumed, and anesthesia was maintained with oxygen, air, propofol, and remifentanil. SBP, DBP, HR, and SpO2 were measured at 5-minute intervals during dental treatment, and adverse events up to one hour after administration of adrenaline-containing lidocaine were examined.

All numerical data are expressed as means \pm standard deviation. Differences in SBP, DBP, HR, and SpO2 between baseline and at each time point were analyzed using Dunnett's test. All statistical analyses were performed using Statistical Package for Social Sciences Version 24.0 (IBM, Armonk, NY). P values $<0.05$ were considered statistically significant.

\section{Results}

The study sample consisted of 30 patients. Patient characteristics are presented in Table 1. All patients were ASA 1, and perioperative data are detailed in Table 2. In four cases, slow induction using sevoflurane was selected, and in the other 26 cases, an intravenous line could be secured.

Changes in SBP, DBP, HR, and SpO2 over time are presented in Figs. 1-3. No significant changes were observed in the SBP, DBP, HR, and SpO2 until 10 minutes after the administration of adrenaline-containing lidocaine. The systolic blood pressure never dropped below $70 \mathrm{mmHg}$ during general anesthesia, and the cardiovascular agent was not administered. No adverse events were observed up to one hour after the administration of adrenaline-containing lidocaine 


\section{Table 1. Patient characteristics}

\section{Patient demographics}

Age (mean $\pm S D$, years)

Sex (male/female)

Weight (mean \pm SD, kg)

Height (mean $\pm \mathrm{SD}, \mathrm{cm}$ )

$\mathrm{BMI}\left(\right.$ mean $\left.\pm \mathrm{SD}, \mathrm{kg} / \mathrm{m}^{2}\right)$

Prescribed Antipsychotics

Butyrophenones

Haloperidol

Bromperidol

Phenothiazine

Propericiazine

Levomepromazine

Atypical antipsychotics

Risperidone

Olanzapine

Aripiprazole

Prescribed reason

Intellectual disability

Autism

Schizophrenia
$24.6 \pm 4.9$

$26 / 4$

$75.4 \pm 19.2$

$168.6 \pm 8.3$

$26.5 \pm 5.9$

n (includes overlaps)

5

1

1

5

16

3

10

n (includes overlaps)

20

16

2

Table 2. Patient perioperative data

Blood concentration of propofol at time of induction $(\mu \mathrm{g} / \mathrm{mL})$

$3.7 \pm 0.8$

Infusion rate of remifentanil at time of induction $(\mu \mathrm{g} / \mathrm{kg} / \mathrm{min})$

$0.25 \pm 0.06$

Rocuronium doses for intubation (mg)

$50.7 \pm 9.4$

Blood propofol concentration at time of adrenaline-containing lidocaine injection $(\mu \mathrm{g} / \mathrm{mL})$

$2.7 \pm 0.5$

Surgical time (min)

$59.8 \pm 33.4$ 


\section{Table 1. Patient characteristics}

Anesthesia time ( $\mathrm{min})$

$113.4 \pm 36.2$

The total dose of propofol $(\mathrm{mg})$

$772.1 \pm 339.5$

The total dose of remifentanil $(\mu \mathrm{g})$

$1083.3 \pm$

572.2

$\mathrm{n}=30$; values are presented as mean $\pm S D$.

\section{Discussion}

In the present study, we assessed changes in the SBP, DBP, $\mathrm{HR}$, and $\mathrm{SpO}_{2}$ until 10 minutes after administrating adrenaline-containing lidocaine to patients taking antipsychotic medications, and no significant changes were noted over time in any measurement. This study demonstrates that adrenaline administered at the standard dose for dental treatment under general anesthesia is unlikely to affect the circulation dynamics of regular antipsychotic users.

Adrenaline is a potent stimulant of both $\alpha$ and $\beta$ adrenergic receptors. $\alpha-1$ adrenergic receptors are located in vascular and cause smooth muscle constriction. However, $\beta-1$ and $\beta-2$ receptors are located in the heart and smooth muscle (vascular, bronchial, and gastrointestinal), respectively. Activation of $\beta$ receptors increases the force and rate of the heart and the relaxation of smooth muscle. The effect of administration of adrenaline in humans is an increase in SBP and HR, while DBP usually decreases. However, when adrenaline is administered in situations where the a-adrenaline receptor has been pharmacologically blocked, $\beta$-adrenergic receptors predominate and may lower blood pressure due to vasodilation; this is known as adrenaline reversal [5].

Antipsychotic drugs have an a-adrenergic receptor blocking action. In Japan, lidocaine hydrochloride solution containing adrenaline for dental procedures have precautions for co-administration; adrenalinecontaining lidocaine should be administered with caution when co-administered with the antipsychotics, such as butyrophenone, phenothiazine, and atypical antipsychotics. This may be because the dose of adrenaline added to lidocaine for dental treatment is smaller than the dose of adrenaline used for medical purposes. In general, 200 to $1000 \mu \mathrm{g}$ of adrenaline is used for medical purposes for highly urgent symptoms, such as advanced cardiac life support and severe asthma attacks. Commercially prepared local anesthetics with adrenaline for dental use are available in local anesthetic cartridges, the most common concentration of adrenaline in lidocaine is $1: 80,000(12.5 \mu \mathrm{g} / \mathrm{mL})$ in Japan. In this study, a $1.8 \mathrm{~mL}$ dental local anesthetic cartridge with an adrenaline concentration of 1:80,000 was administered, for a total dose of $22.5 \mu \mathrm{g}$ of adrenaline.

Some previous reports have shown a drug interaction between adrenaline and chlorpromazine (phenothiazine antipsychotic). Yagiela et al. [7] reported hemodynamic changes caused by a drug interaction between adrenaline and chlorpromazine in dogs. They found that low-dose adrenaline 
$(0.33 \mu \mathrm{g} / \mathrm{kg})$ did not influence blood pressure or heart rate; however, high-dose adrenaline $(2.5 \mu \mathrm{g} / \mathrm{kg})$ induced hypotension and tachycardia. Higuchi et al. [8] also reported intraperitoneal injection of chlorpromazine followed by intraperitoneal injection of adrenaline in rats resulted in marked hypotension and tachycardia depending on the dose of adrenaline; However, administration of chlorpromazine and propranolol, a non-selective beta-blocker, followed by administration of adrenaline only resulted in a slight increase in blood pressure and did not cause a decrease in blood pressure. These animal studies, therefore, provide that hypotension was caused by a drug interaction between adrenaline and chlorpromazine through the activation of the $\beta$-adrenergic receptor and showed a dose-dependent effect.

A low-dose adrenaline $(0.33 \mu \mathrm{g} / \mathrm{kg})$ did not cause hemodynamic changes in the study by Yagiela et al. [7], and the result of applying this dose to the average body weight $(75.4 \mathrm{~kg})$ of the participating patients in this study was $24.8 \mu \mathrm{g}$; this dose is close to the dose in our study $(22.5 \mu \mathrm{g})$. In addition, it is necessary to consider whether canine doses are comparable to human doses, but our findings are consistent with Yagiela et al. and suggest that there was no change in hemodynamics [7]. These findings suggest that a clinical amount of low dose adrenaline used with lidocaine in dental treatment does not show a strong $\beta$ receptor stimulatory effect even when used in patients taking antipsychotics, and does not induce severe hypotension.

The patients taking antipsychotics such as schizophrenia, autism, and intellectual disability are often indicated for dental treatment under general anesthesia because of their noncooperative nature, poor compliance, or dental phobia. The concomitant use of adrenaline and volatile anesthetic can cause increased myocardial irritation and develop cardiac arrhythmias $[9,10]$. Therefore, we chose propofol as a general anesthetic agent. In general, propofol affects the cardiovascular system. Propofol does not directly induce bradyarrhythmias because it does not depress sinoatrial node activity or atrioventricular conduction at therapeutic dose [11]. However, propofol shows a simultaneous decrease in heart contractility and afterload reduction, which leads to hypotension. This resulting hypotension involves significant reductions in systolic, diastolic, and mean arterial pressures $[12,13]$. Therefore, it is presumed that during general anesthesia with propofol, blood pressure is more likely to decrease due to the interaction between antipsychotics and adrenaline than during common dental treatments.

In this study, we consider that propofol did not enhance blood pressure reduction due to the interaction of antipsychotics with adrenaline because all subjects were ASA I and young, and anesthetic depth was maintained using a BIS monitor. However, it cannot be ruled out that severe hypotension may occur when propofol, antipsychotics, and adrenaline are used in combination in patients with low cardiovascular reserves and/or elderly patients. When using adrenaline-containing lidocaine, it is important to monitor hemodynamics at all times.

Furthermore, remifentanil, an opioid analgesic, used during anesthesia induction and tracheal intubation in this study can cause hypotension and bradycardia [14]. The context-sensitive half-time (i.e., the time required for the drug's plasma concentration to decrease by $50 \%$ after cessation of an infusion) of remifentanil is short [15]. Therefore, in our protocol, remifentanil was discontinued immediately after 
intubation, and lidocaine with adrenaline was administered 5 minutes after intubation, such that the effect of the circulatory hemodynamic response of remifentanil was considered negligible at the time of measurement. During dental treatments, the sting from the needle is occasionally associated with systemic complications, such as the vasovagal reflex, ischemic heart disease, and arrhythmias [16]. Even under general anesthesia, it was a possibility that bradycardia was induced by an intense noxious stimulus when infiltrated into the oral submucosa with a large needle, strong pressure, and rapidly by hand [17]. In this study, we believe that a vasovagal reflex was avoided because we performed local anesthesia slowly with a small needle.

This study has some limitations. First, our sample size was relatively small, which may have limited its statistical power. Secondly, among the antipsychotics, the strength of the a1 receptor blocking action differs for each drug. For example, phenothiazines have a stronger a1 receptor blocking effect than butyrophenones and atypical antipsychotics $[18,19]$. Therefore, we need further rigorous studies to examine the interaction with adrenaline according to each type of antipsychotics.

\section{Conclusion}

This is the first prospective study of the effects of the interaction between adrenaline-containing lidocaine and antipsychotics on circulatory dynamics. The injection of commonly used adrenaline-containing lidocaine at clinically-relevant concentrations $(12.5 \mathrm{mg} / \mathrm{mL})$ under general anesthesia is unlikely to affect the circulation dynamics of regular antipsychotic users.

\section{Declarations}

List of abbreviations: ASA: American Society of Anesthesiologists; DBP: Diastolic blood pressure; HR: Heart rate; SBP: Systolic blood pressure; Sp02: Percutaneous oxygen saturation

Ethics approval and consent to participate: All procedures performed in studies involving human participants were in accordance with the ethical standards of the institutional and/or national research committee and with the 1964 Helsinki declaration and its later amendments or comparable ethical standards. This study was approved by the Ethics Committee of The Nippon Dental University School of Life Dentistry Tokyo, Japan (approval number NDU-T-2015-14). It was conducted after clinical trial registration as certified by the International Committee of Medical Journal Editors (trial identification number UMIN000016644). Informed consent: Informed consent was obtained from all individual participants included in the study.

Consent for publication: Not applicable.

Availability of data and materials: Reasonable requests for access to the datasets used and/or analyzed during the study can be made to the corresponding author.

Competing interests: The authors declare that they have no competing interests. 
Funding: This study did not receive any specific grant from funding agencies in the public, commercial, or not-for-profit sectors.

Authors' contributions: All authors have read and approved the manuscript. YS: patient recruitment, data collection, writing up draft of the paper. EN: patient recruitment, data collection. GT: data collection, data analysis and interpretation. TK: patient recruitment, data collection. AY: patient recruitment, data collection. KN: revision of draft of the paper. KS: study design, supervision.

Acknowledgments: We thank the research staff at the Department of Dental Anesthesia, The Nippon Dental University Hospital, Tokyo, for their support.

\section{References}

1. Sorensen WT, Wagner N, Aarup AT, Bonding P. Beneficial effect of low-dose peritonsillar injection of lidocaine-adrenaline before tonsillectomy. Auris Nasus Larynx. 2003;30:159-62.

2. Cassidy JP, Phero JC, Grau WH. Epinephrine: systemic effects and varying concentrations in local anesthesia. Anesth Prog. 1986;33(6):289-97.

3. Yagiela JA. Vasoconstrictor agents for local anesthesia. Anesth Prog. 1995;42(3-4):116-20.

4. Braid DP, Scott DB. Effect of adrenaline on the systemic absorption of local anaesthetic drugs. Acta Anaesthesiol Scand Suppl. 1966;23:334-46.

5. Meyer JM: Goodman \& Gilman's: The Pharmacological Basis of Therapeutics Pharmacotherapy of psychosis and mania. 12th ed. New York: McGraw-Hill; 2011.

6. Okada Y, Ishi W, Narumiya H, Liduka R. Unexpected hypotension in catecholamine reversal: a case report. J Med Case Rep. 2017;11:285.

7. Yagiela JA, Duffin SR, Hunt LM. Drug interactions and vasoconstrictors used in local anesthetic solutions. Oral Surg Oral Med Oral Pathol. 1985;59:565-571.

8. Higuchi H, Yabuki A, Ishii-Maruhama M, Tomoyasu Y, Maeda S, Miyawaki T. Hemodynamic changes by drug interaction of adrenaline with chlorpromazine. Anesth Prog. 2014;61:150-4.

9. Johnston RR, Eger El II, Wilson C. A comparative interaction of epinephrine with enflurane, isoflurane, and halothane in man. Anesth Analg. 1976;55:709-12.

10. Navarro R, Weiskopf RB, Moore MA, Lockhart S, Eger El, Koblin D, et al. Humans anesthetized with sevoflurane or isoflurane have similar arrhythmic response to epinephrine. Anesthesiology. 1994;80:545-9.

11. Romano R, Ciccaglioni A, Fattorini F, Quaglione R, Favaro R, Arcioni R, et al. Effects of propofol on the human heart electrical system: a transesophageal pacing electrophysiologic study. Acta Anaesthesiol Scand. 1994;38:30-2.

12. Gauss $\mathrm{A}$, Heinrich $\mathrm{H}$, Wilder-Smith $\mathrm{OH}$. Echocardiographic assessment of the haemodynamic effects of propofol: a comparison with etomidate and thiopentone. Anaesthesia. 1991;46:99-105. 
13. Cillo JE Jr. Propofol anesthesia for outpatient oral and maxillofacial surgery. Oral Surg Oral Med Oral Pathol Oral Radiol Endod. 1999;87:530-8.

14. Hogue CW Jr, Bowdle TA, O'Leary C, Duncalf D, Miguel R, Pitts M, et al. A multicenter evaluation of total intravenous anesthesia with remifentanil and propofol for elective inpatient surgery. Anesth Analg. 1996;83:279-85.

15. Kapila A, Glass PS, Jacobs JR, Muir KT, Hermann DJ, Shiraishi M, et al. Measured context-sensitive half-times of remifentanil and alfentanil. Anesthesiology. 1995;83:968-75.

16. Matsuura H. Systemic complications and their management during dental treatment. Int Dent J. 1989;39:113-21

17. Satoh K, Ohashi A, Kumagai M, Hoshi H, Otaka K, Joh S. Severe bradycardia possibly due to a local anesthetic oral mucosal injection during general anesthesia. Case Rep Dent. 2015;896196.

18. Hardman JG, Limbird LE. Goodman \& Gilman's The Pharmacological Basis of Therapeutics. 10th ed. New York: McGraw Hill; 2001.

19. Drici MD, Priori S. Cardiovascular risks of atypical antipsychotic drug treatment. Pharmacoepidemiol Drug Saf. 2007;16(8):882-90.

\section{Figures}

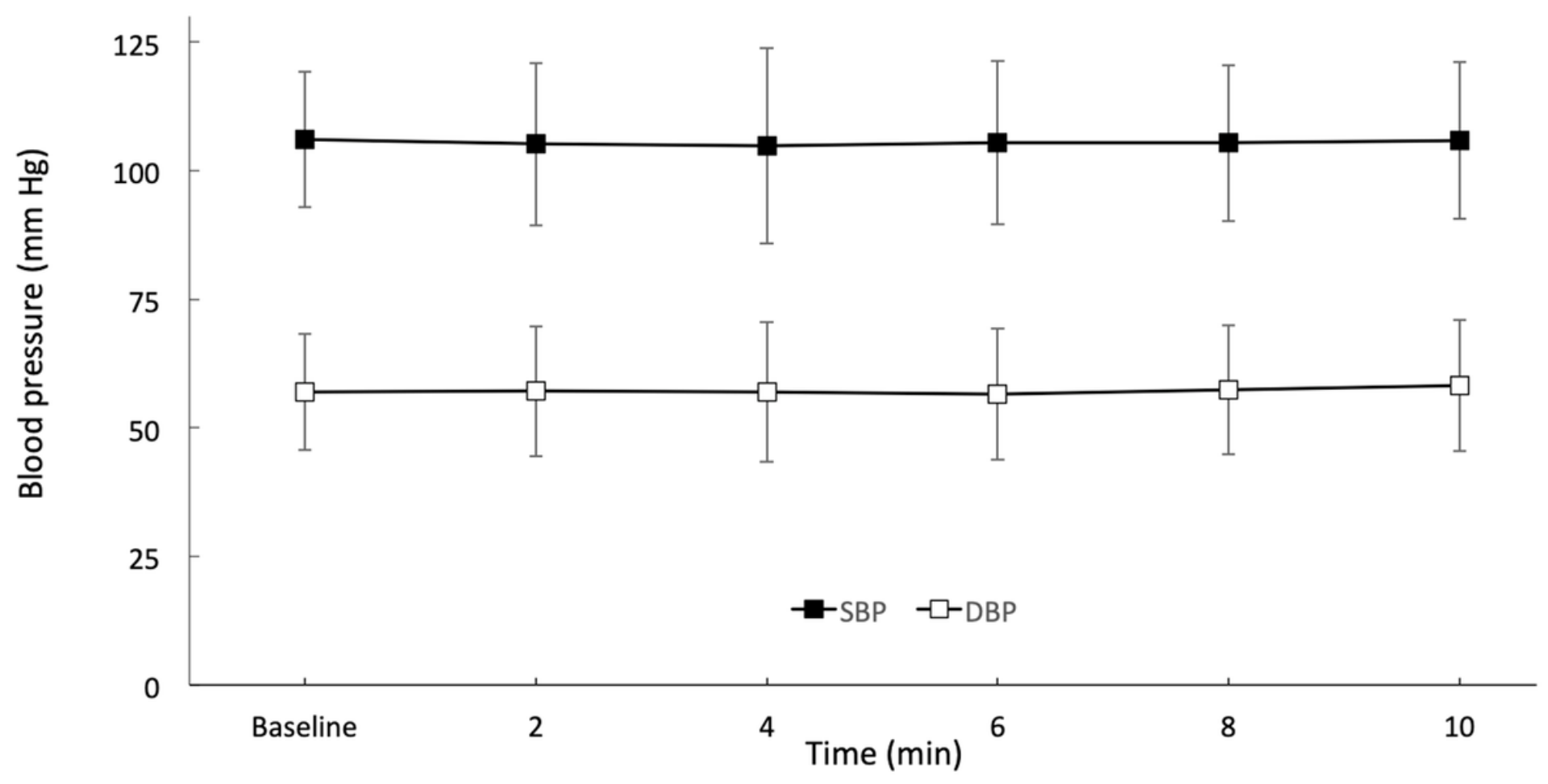

\section{Figure 1}

Changes in systolic blood pressure (SBP, filled squares) and diastolic blood pressure (DBP, open squares) Error bars represent standard deviation $(n=30)$. No significant differences in SBP and DBP were noted 
over time. Baseline; Before adrenaline-containing lidocaine injection. Values are expressed as mean \pm standard deviation. Statistical analysis; Dunnett's test between baseline and at each time point. P-values $<0.05$ were considered statistically significant

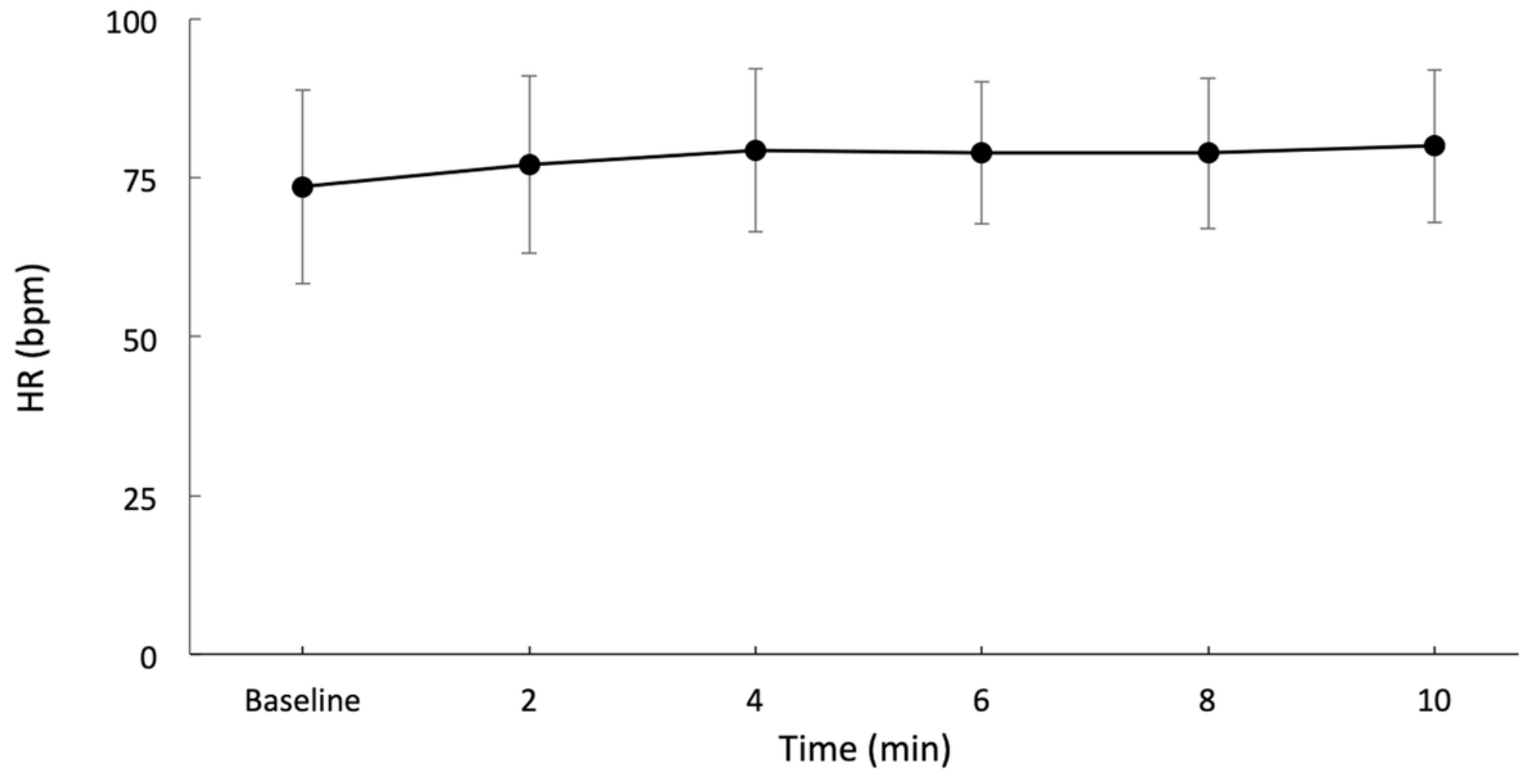

Figure 2

Changes in heart rate (HR, filled circles) over time Error bars represent standard deviation $(n=30)$. No significant differences in HR were noted over time. Baseline; Before adrenaline-containing lidocaine injection. Values are expressed as mean \pm standard deviation. Statistical analysis; Dunnett's test between baseline and at each time point. P-values $<0.05$ were considered statistically significant 


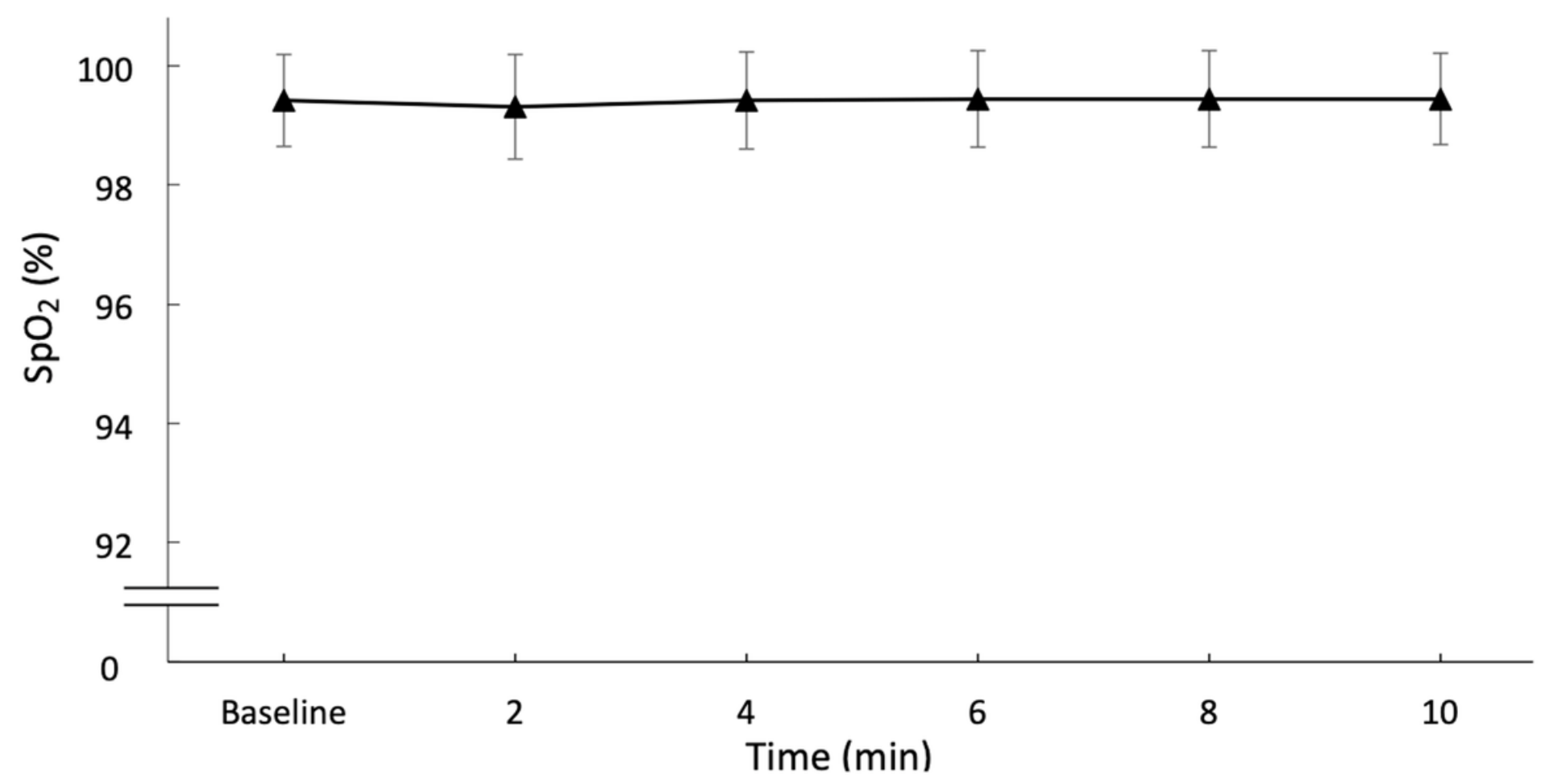

\section{Figure 3}

Changes in percutaneous oxygen saturation ( $\mathrm{SpO} 2$, filled triangles) over time Error bars represent standard deviation $(n=30)$. No significant differences in SpO2 were noted over time. Baseline; Before adrenaline-containing lidocaine injection. Values are expressed as mean \pm standard deviation. Statistical analysis; Dunnett's test between baseline and at each time point. P-values $<0.05$ were considered statistically significant 